\title{
The Effectiveness of High Resolution Ultrasonography in Assessment of Knee Peri-Articular Lesions: Comparative Study to MRI
}

\author{
HAZEM HAMED SOLIMAN, M.D. \\ The Department of Radiology, Faculty of Medicine, Cairo University, Egypt
}

\begin{abstract}
Background: Knee pain is considered one of the main causes of referral to the Radiology Department. Many of the cases have abnormalities within or around the joint following an acute injury or chronic symptomatology.

Ultrasound is a reliable method for detection of injury to the tendons, ligaments, and muscles of the knee joint with its capability to evaluate peri-articular lesions. The periarticular structures are best suitable for ultrasonography evaluation including peri articular masses, joint effusion and bursae.

Aim of Study: The goal of our study is to evaluate role of high resolution ultrasonography in assessment of knee peri articular disorders compared to MR imaging.

Patients and Methods: Our study included 61 patients between March 2018 and April 2019 with 14 patients having bilateral knee joint examinations. They included 37 females and 24 males with their ages ranging between 11-70 years. All of them suffering from painful knee joint with peri-articular lesions. Patients were referred to the Radiology Department at Kasr Al-Aini Hospital after full clinical examination to evaluate their knee joints using US and MRI.

Results: High resolution ultrasonography had sensitivity and specificity ranging from 83 to 100 and $100 \%$ respectively with Positive Predictive Value (PPV) of $100 \%$, Negative Predictive Value (NPV) and accuracy above $95 \%$.

Conclusion: The high correlation rate between the results of US and MRI have shown that in patients with knee joint peri-articular lesions, US is an effective alternative/ complimentary method of examination in detection of knee joint peri articular injuries, cystic and solid mass lesions.
\end{abstract}

Key Words: Ultrasonography - Knee joint - Peri articular lesions.

\section{Introduction}

THE knee joint is one of the most accessible joints for ultrasonography assessment, because the struc-

Correspondence to: Dr. Hazem Hamed Soliman, The Department of Radiology, Faculty of Medicine, Cairo University, Egypt tures examined are superficial thus with minimal interference to the ultrasound waves [1]

High-resolution Ultrasonography (US) is being applied increasingly to musculoskeletal medicine. It has been proved to be diagnostic in the assessment of arthritis patients [2].

Magnetic Resonance Imaging (MRI) is considered the gold standard modality for most of knee lesions, yet ultrasound shows some advantages over MRI [3]

The ultrasound machine is generally less expensive, with no radiation, views in multiple planes, convenient, and has no contra-indications. In addition it allows a dynamic examination which helps to localize musculoskeletal pathologies [4].

Peri-articular knee lesions are one of the most common symptoms for referral to the Radiology Department after knee pain [5] .

\section{Patients and Methods}

The study was allowed by the Hospital Ethical Committee. This study included 61 patients with 14 patients having bilateral knee examinations between March 2018 to April 2019. They included 37 females and 24 males with their ages ranging between 11-70 years. All of them suffering from painful knee joint with peri-articular lesions. $\mathrm{Pa}-$ tients were referred to the radiology department at Kasr Al-Aini Hospital after full clinical examination to evaluate their knee joints using US and MRI.

Ultrasonography of the knee joints was performed using GE, LOGIQ P6 Pro ultrasound ma- 
chine using linear array transducer with frequency of $8-12 \mathrm{MHz}$.

The routine US examination of the knee starts with its anterior aspect, followed by the medial, lateral and posterior aspects in both longitudinal and transverse planes.

MRI was performed using Philips, Achieva or Intera scanners (1.5T) by knee coils in all cases.

The MRI study included the following pulse sequences:

- Sagittal T1WIs.

- Sagittal T2 WIs.

- Sagittal PD WIs.

- Axial T2WIs.

- Coronal T2 FFE WIs.

- T1 post contrast (axial, sagittal and coronal planes) if used.

\section{Inclusion criteria:}

Any patient complaining of knee pain with suspected peri-articular lesions.

\section{Exclusion criteria:}

Patients with absolute contraindications to MR examination as cardiac pace maker, aneurysmal clipping and claustrophobia.

\section{Data analysis and interpretation:}

The knee joint collateral ligaments and peri articular lesions were assessed by ultrasound and MRI. The results of both examinations were interpreted blindly and compared by two experienced radiologists. MRI was considered as gold standard tool.

\section{Results}

Ultrasound detected Medial Collateral Ligament (MCL) injury in 6 knee joints but MRI detected it in 7 knee joints. Both modalities were concordant in 6 patients, and ultrasound missed MCL injury in 1 joint which was detected by MRI. This makes the sensitivity $=85 \%$, specificity $=100 \%$, Positive Predictive Value $(\mathrm{PPV})=100 \%$, Negative Predictive Value $(\mathrm{NPV})=98.5 \%$ and accuracy $=98.6 \%$.

Ultrasound detected LCL injury in 10 knee joints while MRI detected it in 12 knee joints. Both modalities agreed in 10 patients, and ultrasound missed LCL injury in 2 joints detected by MRI. This makes the sensitivity $=83.3 \%$, specificity $=$ $100 \%, \mathrm{PPV}=100 \%, \mathrm{NPV}=96.9 \%$ and accuracy $=$ $97.3 \%$.
Ultrasound detected tendinous lesions in 10 knee joints while MRI detected it in 12 knee joints. Both modalities were concordant in 10 patients, ultrasound missed tendinous lesions in 2 joints detected by MRI (Table 1). This makes the sensitivity $=83.3 \%$, specificity $=100 \%, \mathrm{PPV}=100 \%, \mathrm{NPV}$ $=96.9 \%$ and accuracy $=97.3 \%$.

The study included 9 patellar tendon lesions ( 7 showed tendinosis and 2 partial tears) as well as two quadriceps and only one semimenbranousus tendons lesions. Ultrasound only missed two cases with patellar tendinosis.

Both MRI and Ultrasound detected and agreed in diagnosis of 21 joints with different types of bursae and 6 joints with periarticular soft tissue lesions (Tables 2,3). The ultrasound didn't miss any of them. This makes the sensitivity, specificity, NPV, PPV and overall accuracy values of US regarding the bursal and peri-articular soft tissue lesions all equal to $100 \%$.

The periarticular lesions detected were two soft tissue sarcomas, one intra muscular hemangioma, one muscular hematoma with para meniscal cyst and ruptured baker's cyst.

Regarding peri articular bursae the study included; 7 deep infra patellar, 13 baker's cyst, one pes anserine and one pre patellar bursa.

Table (1): The distribution of the bursal lesions detected.

\begin{tabular}{lccc}
\hline \multirow{2}{*}{ Injury } & \multicolumn{3}{c}{ Distribution } \\
\cline { 2 - 4 } & Patellar & Quadriceps & Semimembranosus \\
\hline Tendinosis & 7 & 1 & 1 \\
Partial tear & 2 & 1 & - \\
\hline Total & 9 & 2 & 1 \\
\hline
\end{tabular}

Table (2): The distribution of the periarticular lesions detected.

Muscular and subcutaneous lesions

Nuber of cases

Soft tissue sarcomas

Intra muscular hemangioma

Rupture baker cyst

meniscal cyst

Intermuscular hematoma

Table (3): The distribution of the bursal lesions detected.

\begin{tabular}{lc}
\hline Bursae & Nuber of cases \\
\hline Deep infra patellar & 7 \\
Prepatellar & 1 \\
Baker's cyst & 13 \\
Pes Anserine & 1 \\
\hline
\end{tabular}



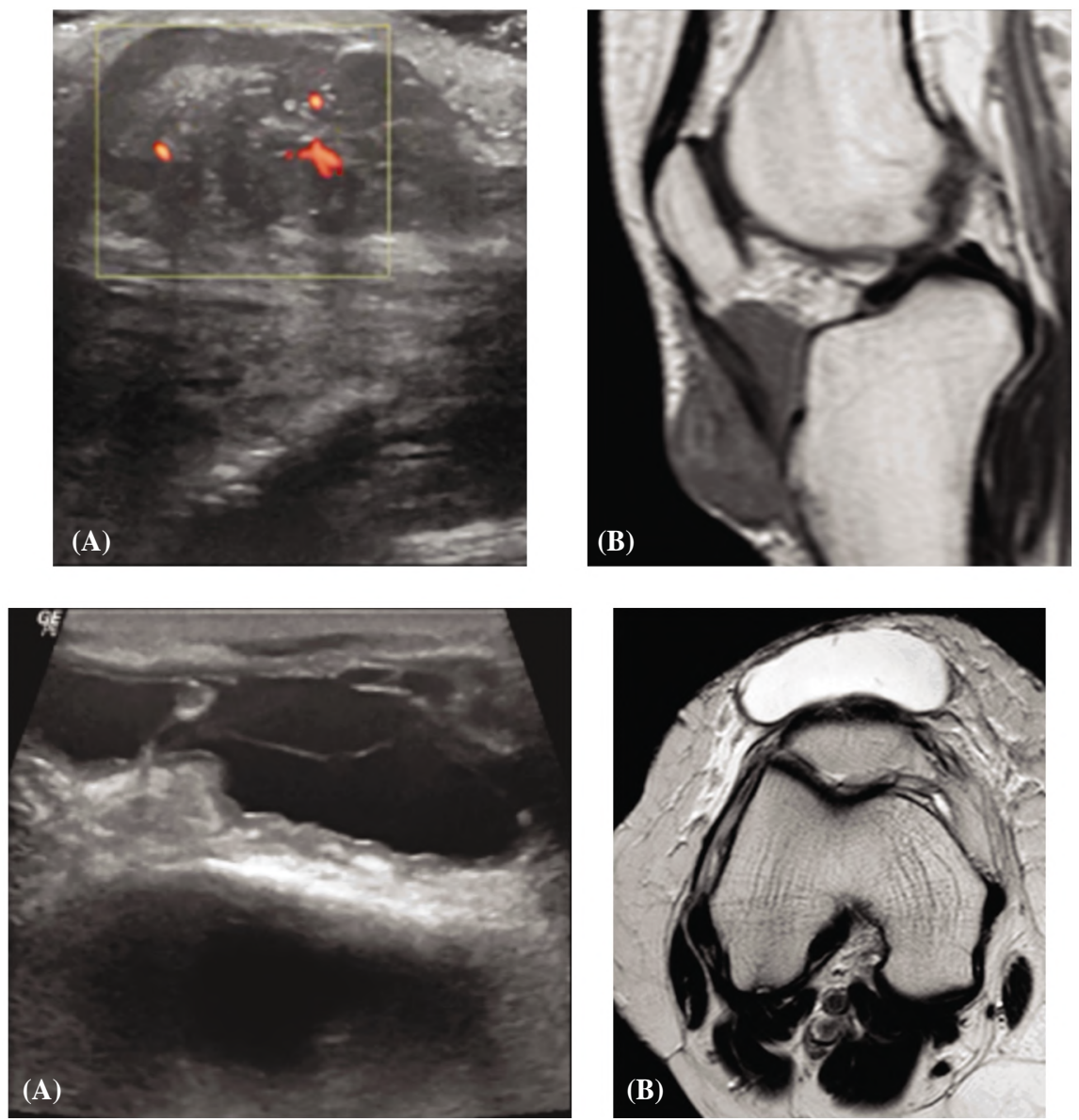

Fig. (1): 22 years old female patient with focal right knee swelling that was pathologically proven to be synovial sarcoma. (A) Grey scale and power Doppler longitudinal US images on the infra patellar region shows a hypoechoic, heterogenous mass lesion with markedly increased vascularity by Doppler study centered upon and infiltrating the patellar tendon. (B) Post contrast Sagittal T1WIs showing heterogeneously enhancing mass lesion centered upon and infiltrating the patellar tendon.

Fig. (2): 44 years old male patient with anterior knee swelling (prepatellar bursitis). (A) Longitudinal gray scale and power Doppler US images showing a septated fluid collection at the pre-patellar subcutaneous fat. (B) Axial T2W images showing a distended pre patellar bursa by fluid signal with thin septae seen within.
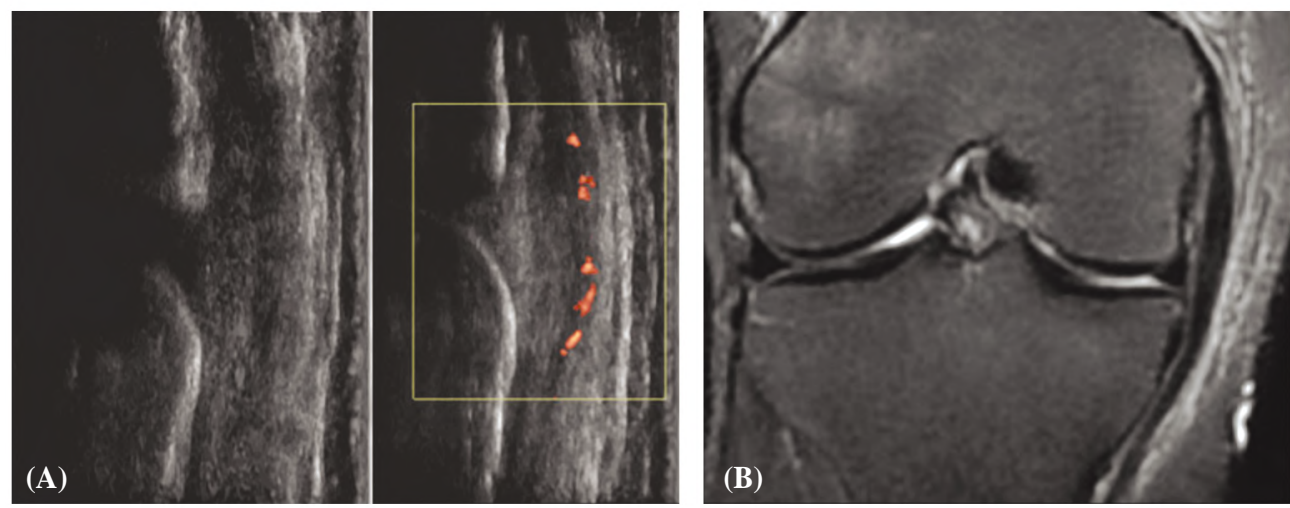

Fig. (3): A female patient 23 years with medial knee pain after trauma. (A) Longitudinal US image over the medial knee region showing thickened medial collateral ligament with heterogeneous hypoechoic texture and increased Doppler signal. (B) Coronal STIR images shows thickened medial collateral ligament with bright signal seen within.
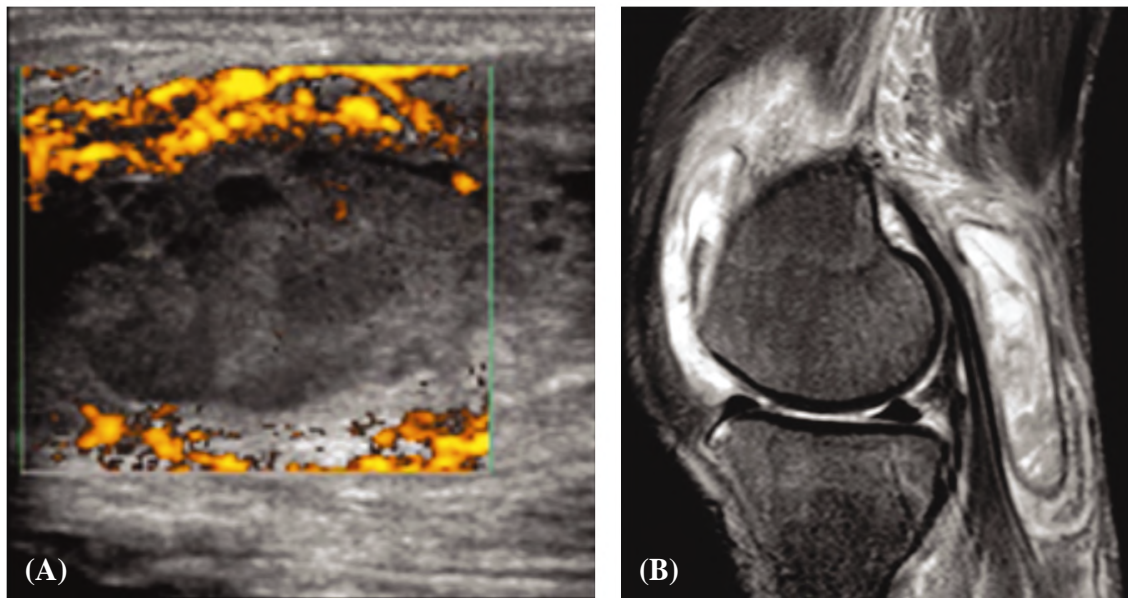

Fig. (4): 41 years old male patient with inflammatory arthritis and knee swelling. (A) Transverse gray scale and power Doppler US images of the Baker's cyst showing synovial thickening with increased vascularity in power Doppler. (B) Sagittal STIR WIs shows joint effusion with synovial thickening at the Baker's cyst. 


\section{Discussion}

In a recent study by Sekiya and his colleagues, [6] they showed $92 \%$ sensitivity and $75 \%$ specificity for US in detecting lateral collateral ligaments injuries. One study done by Lee and his colleagues [7] showed that the sensitivity of sonography in the detection of MCL injuries was approximately $94 \%$.

These results were concordant with our results in the diagnosis of collateral ligaments injuries by ultra sound. Our study showed that the US is $85 \%$ sensitive and $100 \%$ specific in the assessment of MCL injuries, and $83 \%$ sensitive and $100 \%$ specific in the assessment of LCL injuries.

In a study done by Khan and his colleagues [8] performed on 24 athletes with patellar tendinosis who underwent tenotomy, the ultrasonographic findings were proven to be consistent with those of both MRI and histopathologic results.

Swen and his collagues [9], also assessed the value of both US and MRI for the detection of partial tears of the tendons in 21 patients. They concluded that both modalities had relatively lower sensitivity for routine use when surgery was used as the gold standard. This matches with our results, as we found US $83 \%$ sensitive, $100 \%$ specific and $97 \%$ accurate in detection of the tendinous lesions in comparison with MRI.

Lakkaraju, and his colleagues [10], did ultrasound evaluation for two hundred consecutive patients referred with masses and stated that Ultrasound is a useful triage tool for the assessment of masses referred.

Bianchi and Martinoli [11], investigated the importance of ultrasound in the assessment of the limbs soft tissue lesions and the concordance rate of sonographic findings with histopathology after biopsy was $57.7 \%$.

Ostergaard and his colleagues [13] which compared ultrasound and MRI showed that ultrasound detected $100 \%$ of effusions and Baker's cysts seen on MRI.

$\mathrm{Wu}$ and his colleagues [12], studied ultrasound in the diagnosis of the muscular soft tissue sarcomas and showed high concordance between sonographic diagnosis and surgical findings.

In our results we found US $100 \%$ sensitive, specific and accurate in detection and anatomical evaluation of the peri articular soft tissue lesions in comparison with MRI and not in correlation with the histopathology.

\section{References}

1- PATIL P. and DASGUPTA B.: Role of diagnostic ultrasound in the assessment of musculoskeletal diseases, Ther. Adv. Musculoskel. Dis., 4 (5): 341-55, 2017.

2- PACZESNY L. and KRUCZYN J.: Ultrasound of the Knee, Seminars in Ultrasound, CT and MRI, Elsevier Ltd, 32: 114-24, 2016.

3- NAREDO E., CABERO F., PALOP M.J., COLLADO P., CRUZ A. and CRESPO M.: Ultrasonographic findings in knee osteoarthritis: A comparative study with clinical and radiographic assessment. Osteoarthritis Cartilage. Jul., 13 (7): 568-74, 2018.

4- McGAHAN J.P. and GOLDBERG B.B.: Musculoskeletal system In Diagnostic ultrasound, second edition, St Louis: Mosby, p.: 735-803, 2015.

5- LEE J.I., SONG I.S. and JUNG Y.B.: Medial collateral ligament injuries of the knee: Ultrasonographic findings. J. Ultrasound Med., 15: 621-5, 2014.

6- SEKIYA J.K., SWARINGEN J.C., WOJTYS E.M. and JACOBSON J.A.: Diagnostic ultrasound evaluation of posterolateral corner knee injuries. j.arthro, 26 (4): 4949, 2019.

7- LEE J.I., SONG I.S. and JUNG Y.B.: Medial collateral ligament injuries of the knee: Ultrasonographic findings. J. Ultrasound Med., 15: 621-5, 2012.

8- KHAN K.M., BONAR F., DESMOND P.M., et al.: Patellar Tendinosis (jumpers knee); Findings at histopathologic examination, US, and MR imaging. Victorian Institute of Sport Tendon. Study Group, Radiology, p: 821-7, 2013.

9- SWEN W., JACOBS J., KLASENS J., ALGRA P. and BILJLSMA J.: Comparison of sonography and magnetic resonance imaging for the diagnosis of partial tears of tendons extensor tendons in rheumatoid arthritis. Rheumatology, 39: 55-62, 2018.

10- LAKKARAJU A., SINHA R., GARIKIPATI R., EDWARD S., et al.: Ultrasound for initial evaluation and triage of clinically suspicious soft-tissue masses. Clinical radiology, 64 (6): 615-21, 2019.

11- BIANCHI S. and MARTINOLI C.: The knee joint in Ultrasound of Musculoskeletal System. Springer-Verlag Berlin Heidelberg, 10: 422-546, 2017.

12- WU L., FOUDA N., ELMETWALEY N. and ELBOGDADY E.: Sonography of the knee joint Journal of Ultrasound, 12: 53-60, 2016.

13- OSTERGAARD M., EJBJERG B. and SZKUDLAREK M.: Imaging in early rheumatoid arthritis: Roles of magnetic resonance imaging, ultrasonography, conventional radiography and computed tomography, Best Practice \& Research Clinical Rheumatology, 19: 91-116, 2012. 


\section{دراسة كفاءة الموجات فوق الصوتية عالية التباين فى تشخيص إعتلالات ما حول مفصل الركبه مقارنة الهوتئ بالرنين المغناطيسى}

الهدف من هذه الدراسة هو تقييم دود الموجات فوق الصوتية عالية التباين المرضى المشتبه بإصابتهم بإعتلالات ما حول مفصل الركبه. آجريت هذه الدراسة فى مستشفيات جامعة القاهرة على الج من المرضى. خضع كل مريض إلى تصوير كامل لمفصل الركبه بإستخدام الموجات فوق الصوتية والرنين المففناطيسى. تم التاكد من تطابق عالى فى النتائج بين الموجات فوق الصوتية والرنين المغناطيسى فى الكثف عن الإعتلالات المتمثة فى آمراض الآربطة والآوتار بالإضافة إلى تكوين الكتل.

يمكن الإستخلاص آن الموجات فوق الصوتية وسيلة هامة ومكملة لفحص الرنين المغناطيسى وذلك لقدرتها على إعطاء صورة ودقيقة فى المرضى المشتبه بإصابتهم بإعتلالات ما حول مفصل الإن الركتيه. 